\title{
Analysis Of Online Customer Reviews
}

James R. Otto, (E-mail: jotto@towson.edu), Towson University

William Wagner, (E-mail: william.wagner@villanova.edu), Villanova University

\begin{abstract}
The overall satisfaction of the customer is an important issue for online retailers. This paper analyzes online customer ratings of electronic goods in the areas of Overall Customer Satisfaction, Customer Service, Delivery, Ease of Purchase, Price, and Shipping Options. The authors develop neural network and multiple regression models that relate Overall Customer Satisfaction evaluations to the other rating factors. By using these models, online retail managers can determine how to best allocate their resources to improve customer service, delivery, ease of purchase, price, and/or shipping options in ways that can best improve overall customer satisfaction.
\end{abstract}

\section{Introduction}

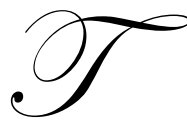

his paper addresses the analysis of customer feedback for online electronic goods retailers (e-tailers). We discuss important publicly available online sources of customer feedback rating information for the electronic goods retail industry. The paper then analyzes the relationships between customer ratings on Overall Customer Satisfaction (the dependent variable), and their views of Customer Service, Delivery, Ease of Purchase, Price, and Shipping Options. By understanding these relationships, an online retailer can determine the best mix of investment in these four areas in order to optimize overall customer satisfaction levels.

Direct online customer feedback, in the form of customer surveys at the point of sale (e.g., right after checkout) and later via email can provide valuable marketing information on how well the e-tailer is doing in the eyes of the consumer.

Open and transparent consumer feedback is becoming an important metric for online retailers. For example, E-bay (Ebay, 2004) provides publicly available customer ratings on Ebay vendors as a way of enhancing trust and reducing fraud (Wingfield, 2002). This publicly available information can be used by customers to make decisions about which vendors to engage, by e-tailers to promote their site and improve customer service, and by competitors for comparative analysis.

The use of online surveys is a natural extension of how e-tailers do business online. It is relatively simple and straightforward to offer electronic surveys to the customer at the time of checkout. The customer is already online and the information about the web site's processes is fresh in the consumer's mind. Later on, email surveys can be sent to the same customer for feedback about post checkout fulfillment processes and service.

\section{Customer Feedback Data Sources}

There are a number of third party entities that offer vendor rating services to include Ebay, Yahoo, Bizrate, and Reseller Ratings (Tynan, 2000). A significant advantage to third party administration of consumer ratings, at least from the consumer perspective, is the credibility of the rating information. Self reporting, or advertising, of customer ratings by a vendor might be more suspect than an independent entity providing the same information. An additional advantage to an independent entity managing vendor ratings is in the area of standardization of data. An intermediary can collect the same type of consumer feedback, using the same methodology, across many vendors. This provides common data that can be compared across different vendors. The different rating service companies are discussed below. 
Yahoo

Yahoo.com provides customer ratings of the vendors that it supports on a scale of 1 (poor) to 5 (excellent) for Overall Satisfaction, Price, Shipping Options, Delivery, Ease of Purchase, and Customer Service. Customers can also provide written comments about the e-tailer. Yahoo reports the average vendor rating rounded to the nearest 0.5. In addition to its rating service, Yahoo.com provides turnkey web storefront and BackOffice services for etailers for fixed monthly fees and variable transaction fees (Yahoo Shopping Help, 2004).

Ebay

Ebay provides a feedback forum that allows buyers to leave positive, neutral, or negative feedback on a seller. Each buyer can only leave one comment per transaction. For each positive comment, the seller's overall feedback rating will advance by one. A neutral comment will not impact it and a negative comment will decrease it by one (EBay Feedback Forum, 2004). Thus, a seller with ten positive, one negative, and two neutral comments will have an overall rating of eight.

Bizrate

Bizrate provides free third party rating services to any e-tailer that signs up. The e-tailer pastes some HTML code into their receipt page. The HTML code produces a survey that pops up after the customer purchases an item. The survey asks for inputs on the shopping experience from 1 (poor) to 10 (outstanding). Bizrate follows up with emails with after-the-sale support rating surveys. Bizrate.com publicly reports on the following factors: Would shop here again, Overall rating, Ease of finding what you are looking for, Selection of products, Clarity of product information, Prices relative to other online merchants, Overall look and design of site, Shipping charges, Variety of shipping options, Charges stated clearly before order submission, Availability of product you wanted, Order tracking, On-time delivery, Product met expectations, and Customer support. Bizrate.com earns money by selling aggregated marketing research on their survey feedback. Since participating with Bizrate.com is voluntary on the part of the e-tailers, the results may be skewed toward more positive reports, since poorly rated vendors may choose to opt out of the rating system (Bizrate Store Ratings, 2004).

\section{Reseller Ratings}

Reseller Ratings provides tools for people to rate stores. Users must provide an invoice number to support the contention that they shopped at the e-tailer. Reseller Ratings reports from 1 to 10 on the following factors: Pricing of Products and Services, Likelihood of Future Purchases, Shipping and Packaging, Technical Support, and Return or Replacement (Reseller Ratings Help, 2004).

The customer evaluation data collected by these online rating services has advantages over traditional data collection methodologies. The data has transparency and is available to all Internet users. The data can be collected immediately while the consumer is in the process of purchasing the product (as well as after sale data collection via email). Using this type of electronic data collection can speed up the data collection and analysis cycle. For example, Yahoo rating data is collected daily and reported weekly (Yahoo Shopping Help, 2004). The rating data for Yahoo is also rather fresh, since it is removed after aging 6 months.

The online rating data also has disadvantages associated with it. While the rating agencies have instituted methods to reduce its potential of occurring, it may still be possible for individuals to "stuff the ballot box" to skew the ratings results (Tynan, 2000). The data, since it is at most 6 months old, only provides a snapshot in time. For the data that we used, it was limited to vendors associated with Yahoo store services. Thus, the data may be skewed by the fact that Yahoo vendors tend to be independent dealers rather than large e-tailer chains. Additionally, the sample can be biased by the fact that the data is collected after completed a purchase. Data is not collected from individuals who have abandoned a shopping experience and thus dissatisfied customers may not reach the survey (Bizrate Store Ratings, 2004). Additionally, many of the rating services have separate relationships with vendors (such as hosting e-tailer sites), which may impact the rating process in subtle ways. 


\section{Approach}

Figure 1 diagrams the approach taken to collect and analyze the data. The first step was to collect the data from the e-tailer rating Web site. This was done using automated software scripts to download the relevant Web pages and extract the appropriate information from the Web pages. The process was automated because the actual collection of the ratings by hand would have been very labor intensive (each individual rating was available on a different Web page). The next step was to organize the data into data tables formatted appropriately for the development of the models. The data sources were then used to develop and train a neural network and to derive a linear regression model to predict the Overall Satisfaction rating based on the other evaluation factors. These models were then analyzed to determine their estimated accuracy against the data.

\section{Figure 1 Data Analysis and Modeling Approach}

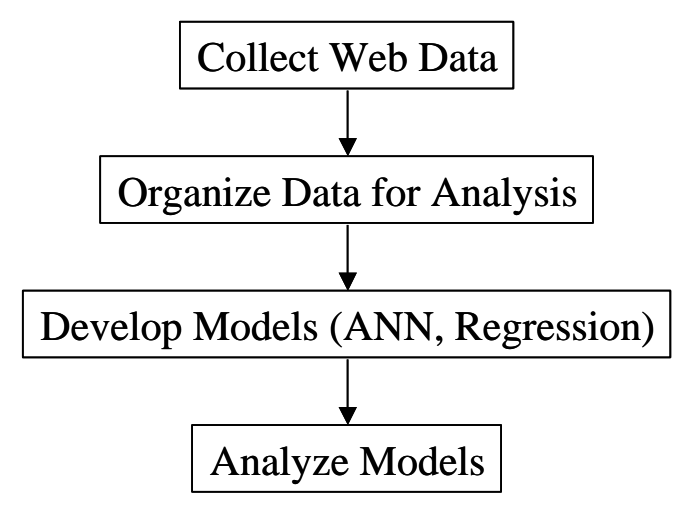

The following publicly available data was collected from Yahoo.com for electronic goods e-tailers (Yahoo Electronics Shopping, 2003). The analysis included 166 vendors that sold electronic goods and had at least 30 customer reviews. The Yahoo customer rating factors shown in Table 1 varied from 1 to 5 (in increments of 0.5). Metadata describing the ratings data is also provided in Table 1.

Two different techniques, neural networks and multiple regression analysis, were employed to develop models on how the Overall Satisfaction rating related to the other customer rating factors (Customer Service, Delivery, Ease of Purchase, Price, and Shipping Options). By using these models, e-tailers can determine how best to employ their limited resources to impact overall satisfaction by impacting the other customer satisfaction input factors.

Neural networks are patterned after the human brain. They operate by creating weighted connections between processing nodes. During training, the connection weights are changed so that over time the system learns to produce a desired output based on specific input values. There are many types of neural networks with several different types of topologies. This analysis developed and trained a backpropogation neural network to develop a model relating the input rating factors to the Overall Satisfaction customer ratings.

Multiple regression models can predict the value of a dependent variable based on several independent input variables and takes the form $Y=a+b_{1} * X_{1}+b_{2} * X_{2}+\ldots+b_{n} * X_{n}$. Multiple regression assumes that the relationships between the independent and dependent variables is linear and that the residuals are normally distributed (Statsoft, 2004). 
Table 1 Customer Ratings Data Statistics

\begin{tabular}{|c|c|c|c|c|c|c|}
\hline & $\begin{array}{c}\text { Overall } \\
\text { Satisfaction }\end{array}$ & Price & $\begin{array}{l}\text { Shipping } \\
\text { Options }\end{array}$ & Delivery & $\begin{array}{c}\text { Ease of } \\
\text { Purchase }\end{array}$ & $\begin{array}{c}\text { Customer } \\
\text { Service }\end{array}$ \\
\hline Mean & 4.31 & 4.47 & 4.28 & 4.35 & 4.53 & 4.25 \\
\hline Standard Error & 0.03 & 0.018 & 0.025 & 0.038 & 0.027 & 0.037 \\
\hline Median & 4.5 & 4.5 & 4.5 & 4.5 & 4.5 & 4.5 \\
\hline Mode & 4.5 & 4.5 & 4.5 & 4.5 & 4.5 & 4.5 \\
\hline Standard Deviation & 0.41 & 0.23 & 0.32 & 0.49 & 0.35 & 0.48 \\
\hline Sample Variance & 0.17 & 0.05 & 0.10 & 0.24 & 0.12 & 0.23 \\
\hline Kurtosis & 3.29 & 1.63 & 1.10 & 4.11 & 2.99 & 3.14 \\
\hline Skewness & -1.55 & -0.22 & -1.07 & -1.56 & -1.13 & -1.36 \\
\hline Range & 2.5 & 1 & 2 & 3 & 2 & 3 \\
\hline Minimum & 2.5 & 4 & 3 & 2 & 3 & 2 \\
\hline Maximum & 5 & 5 & 5 & 5 & 5 & 5 \\
\hline Sum & 716 & 742 & 711 & 722.5 & 753 & 706 \\
\hline Count & 166 & 166 & 166 & 166 & 166 & 166 \\
\hline
\end{tabular}

\section{Analysis Results}

The following neural network and multiple regression models were generated from the data. A backpropogation neural network model of Overall Satisfaction as a function of the other rating factors was developed using 50\% random training sample. The model consisted of 27 input layer nodes, 3 hidden layer nodes, and 6 output layer nodes. The accuracy of the neural network is $87 \%$. A multiple regression model was also developed with Overall Satisfaction as the dependent variable. The developed model is:

Overall Satisfaction $=($ Customer Service $* 0.4906)+($ Delivery $* 0.1995)+($ Ease of Purchase $* 0.04443)+($ Price $*$ $0.1228)+($ Shipping Options * 0.07469) $+(0.2887)$

A summary of the multiple regression model is provided in Table 2 below.

Table 2 Summary of Multiple Regression Model

\begin{tabular}{|l|c|c|c|}
\hline R & R Square & Adjusted R Square & Std. Error of the Estimate \\
\hline .902 & .814 & .809 & .1809 \\
\hline
\end{tabular}

As can be seen from the ANN accuracy of $87 \%$ and the multiple regression model R-value of .902 , the models do a good job of predicting Overall Satisfaction given the other input factors. However, it should be cautioned that although the models do a good job of prediction for the range of data values used to develop them, predicting outside the values used to develop them may be inappropriate. As can be seen from Table 1, the mean ratings for all inputs fell between 4.25 and 4.5 and the minimum rating for any factor was 2 out of 5 . Thus, using the model for rating values lower than 3 may result in inaccurate outputs.

\section{Management implications}

These models can help a manager determine how best to deploy company resources to impact the input rating factors in order to optimize customer satisfaction. For example, a cursory inspection of the multiple 
regression model shows that the Customer Service rating provides the largest impact on the Overall Customer Satisfaction rating. This notion is reinforced by examining the correlation matrix provided in Table 3, which shows that Customer Service (0.89) has a higher correlation with Overall Customer Satisfaction then the other input factors. Thus, if the unit cost of increasing the customer service rating is on a par with the cost of increasing the other input rating factors, then improving customer service would probably make the most investment sense.

Table 3 Correlation Matrix

\begin{tabular}{lcccccc}
\hline & $\begin{array}{c}\text { Overall } \\
\text { Satisfaction }\end{array}$ & Price & $\begin{array}{c}\text { Shipping } \\
\text { Options }\end{array}$ & Delivery & $\begin{array}{c}\text { Ease of } \\
\text { Purchase }\end{array}$ & $\begin{array}{c}\text { Customer } \\
\text { Service }\end{array}$ \\
\hline Overall Satisfaction & 1 & & & & & \\
Price & 0.49 & 1 & & & & \\
Shipping Options & 0.74 & 0.42 & 1 & & & \\
Delivery & 0.84 & 0.47 & 0.77 & 1 & & \\
Ease of Purchase & 0.78 & 0.49 & 0.70 & 0.81 & 1 & \\
Customer Service & 0.89 & 0.47 & 0.77 & 0.85 & 0.83 & 1 \\
\hline
\end{tabular}

\section{Summary, Conclusions, and Future Research}

This paper analyzed online customer ratings of electronic goods e-tailers to develop neural network and multiple regression models that predict, with good accuracy, customer Overall Satisfaction ratings based on user ratings of Customer Service, Delivery, Ease of Purchase, Price, and Shipping Options. These models can be used to support management decisions on how to apportion investments across these different factors. An important area for future research would be to evaluate the stability of the models (how much they may change) over time.

\section{References}

1. Bizrate Store Ratings. (n.d.). Retrieved January 14, 2004 from http://shop.bizrate.com/ratings_guide/ guide.xpml. Ebay Feedback Forum. (n.d.). Retrieved January 3, 2004 from http://pages.ebay.com/ services/forum/feedback.html.

2. Reseller Ratings Help. (n.d.). Retrieved January 5, 2004 from http://www.resellerratings.com/faq.pl.

3. Statsoft. (n.d.). Multiple Regression. Retrieved January 25, 2004 from http://www.statsoft.com/ textbook/stmulreg.htmlTynan, D. (2002). Power shopping: can you trust e-commerce review sites? PC World, 18/7, pp. 60-61.

4. Wingfield, N. (2002, September 16). Are You Satisfied? --- Ebay's battle against fraud rests primarily on a simple concept: customer feedback. Wall Street Journal, p. R.7.

5. Yahoo Electronics Shopping. (n.d.). Retrieved December 31, 2003 from http://shopping.yahoo.com/ stores/sd.html.

6. Yahoo Shopping Help. (n.d.). Retrieved January 23, 2004 from http://help.yahoo.com/help/us/shop/shop86.html. 
$\underline{\text { Notes }}$ 